\title{
Amino-Functionalization of Multiwall Carbon Nanotubes and Its Use for Solid Phase Extraction of Mercury Ions from Fish Sample
}

\author{
Majid Soleimani, Majid Ghahraman Afshar, and Arman Sedghi \\ Department of Chemistry, Imam Khomeini International University (IKIU), P.O. Box 288, Qazvin 34149-16818, Iran \\ Correspondence should be addressed to Majid Soleimani; m-soleimani@hotmail.com
}

Received 11 May 2013; Accepted 7 June 2013

Academic Editors: G. Alfieri, Y. A. Koksharov, W. Mamdouh, X. Qin, Z. Shi, and H. Tang

Copyright (C) 2013 Majid Soleimani et al. This is an open access article distributed under the Creative Commons Attribution License, which permits unrestricted use, distribution, and reproduction in any medium, provided the original work is properly cited.

\begin{abstract}
We describe here the amino-functionalization of multiwall carbon nanotubes (MWCNTs) and also its application as an adsorbent of solid phase extraction (SPE). The amino-functionalized MWCNTs have a good capacity to retain $\mathrm{Hg}^{2+}$, but the raw and purified MWCNTs are found not to adsorb $\mathrm{Hg}^{2+}$ ions. The amino-functionalized MWCNTs are prepared with amino-functionalization of purified MWCNTs by ethylenediamine. The physicochemical properties of purified and amino-functionalized MWCNTs are characterized by Fourier transform infrared spectroscopy, thermogravimetric analysis, and the Boehm titration. The aminofunctionalized MWCNTs are selected as novel sorbents for the solid phase extraction of $\mathrm{Hg}^{2+}$. The amino-functionalized MWCNTSPE method is used for the determination of $\mathrm{Hg}^{2+}$ from complex matrix including fish and real water samples. Effective parameters on $\mathrm{Hg}^{2+}$ retention such as $\mathrm{pH}$, flowrate, nature of the eluent, the ionic strength, selectivity coefficient, and retention capacity are investigated. The enrichment factor and maximum capacity of the sorbent are $100 \mathrm{~mL}$ and $11.58 \mathrm{mg} / \mathrm{g}$, respectively. The linear range, limit of detection, and relative standard deviation of the proposed method are 0.003 to $0.3 \mu \mathrm{g} / \mathrm{L}, 1.25 \times 10^{-3} \mu \mathrm{g} / \mathrm{L}$, and $2.23 \%$, respectively. Selectivity experiments show that the adsorbents have a stronger specific retention for $\mathrm{Hg}^{2+}$ than $\mathrm{Fe}^{3+}, \mathrm{Cu}^{2+}, \mathrm{Pb}^{2+}$, $\mathrm{Ni}^{2+}, \mathrm{Mn}^{2+}, \mathrm{Ca}^{2+}$, and $\mathrm{Mg}^{2+}$.
\end{abstract}

\section{Introduction}

Mercury presents as different species in different environmental media including atmosphere, soil, sediment, natural waters, waste water, and water body. Mercury pollution in water has a negative impact on the aquatic organism and human. Speciation of mercury in water is very important for evaluation of mercury pollution $[1,2]$. Mercury is also a kind of environmental hormone, which can destroy the functions of natural metabolism and incretion, procreate for organism, and lead to maladjustment in hormone secretion of organism. At the same time, mercury is widely dispersed in natural world because of its extensive applications [3]. It is well known that mercury is one of the most toxic heavy metals. In contaminated environment, different forms of mercury can be accumulated in animals and plants and also enter into human body by food cycle, resulting in the damage of central nerve. Because of mercury accumulative and persistent character in the environment and living organisms, lethal concentrations of mercury salts range from less than $0.1 \mathrm{ng} / \mathrm{mL}$ to more than $200.0 \mathrm{ng} / \mathrm{mL}$ for marine species and freshwater organisms [4]. Mercury is a nonessential toxic element and is known to affect the central nervous system in a number of ways. Food is a major source of mercury intake, especially in areas where fish and other seafood are the main components of the diet.

It is therefore clear that total mercury and organomercury, particularly methylmercury, levels in food should be determined [5]. Because of low concentration of mercury species and complexity of the environmental samples matrix, an enrichment step is usually necessary before separation and detection [1]. The determination of $\mathrm{Hg}^{2+}$, presents at trace or ultratrace levels especially in natural matrices needs two basic steps. The first is a selective separation step to remove matrix 
interference, and the second is an efficient preconcentration to meet the detection limits required for its determination mode.

Generally, several methods have been used for preconcentration of trace amounts of metal ions in aqueous solutions including liquid-liquid extraction, solid phase extraction (SPE), solid phase micro-extraction, liquid phase microextraction [1], cloud point extraction, precipitation, membrane filtration, and floatation separation [3].

In fact, SPE has become known as a powerful tool for separation and enrichment of various inorganic and organic analytes. The basic principle of SPE is the transfer of the analyte from the aqueous phase to bind to active sites of the adjacent solid phase. It has several advantages over other techniques, including stability and reusability of the solid phase, reach of high preconcentration factors, easiness of separation and enrichment under dynamic conditions, no need for organic solvents which may be toxic, and minimal costs due to low consumption of reagents. Accordingly, several selective solid phase extractors have been prepared either by physical loading or chemical binding of selected chelating reagents to different solid supports such as silica gel, activated carbon, cellulosic derivatives, polyurethane foam, chelating ion exchange resins, naphthalene alumina, activated carbon, fly ash, peat, sewage sludge ash, zeolite, biomaterials, recycled alum sludge, manganese oxides, peanut hulls, kaolinite, and resins [6]. However, these adsorbents suffer from low adsorption capacities or removal efficiencies of metal ions. Therefore, researchers carried out investigation for new promising adsorbents.

Carbon nanotubes had been discovered by Iijima. The hexagonal arrays of carbon atoms in graphite sheets of carbon nanotubes surface are ideal for strong interactions with other molecules [7]. The advantages of carbon nanotubes are unique structural, electronic, optoelectronic, semiconductor, metallic, mechanical, and chemical large specific surface area, hollow and layered structures, and physical properties. Carbon nanotube would impact future nanoscience and nanotechnology since it is a highly potential material and has become available in macroscopic quantities.

Carbon nanotubes are divided into two types: (1) singlewalled carbon nanotubes and (2) MWCNTs. Carbon nanotubes walls are not reactive, but their fullerene-like tips are known to be more reactive, so end functionalization of carbon nanotubes is used relatively often to generate functional groups (e.g., $-\mathrm{COOH},-\mathrm{OH}$, or $-\mathrm{CO}$ ). Carbon nanotubes have attracted great attention in latent applications such as nanodevices, field emission, gas adsorption, composite reinforcement, metal (ion) nanocomposites, and catalyst supports as they possess exceptional mechanical properties, unique electrical properties, high chemical and thermal stability, and a large specific surface area. The applications of carbon nanotubes have been extensively employed in the various detection devices, for example, in electrochemical detectors, gas sensors, and biosensors with immobilized biomolecules. Their applications are favorable in voltammetric and electrochemical stripping methods [8-13].

Because of their highly porous and hollow structure, large specific surface area, and light mass density, carbon nanotubes have been investigated for the removal of organic pollutions, metal ions, and some radionuclides such as $\mathrm{Pb}^{2+}$ $[5,6,14-16], \mathrm{Cd}^{2+}[9,16], \mathrm{Cu}^{2+}[8,11,16,17], \mathrm{Ni}^{2+}[10,17]$, $\mathrm{Zn}^{2+}[17-19], \mathrm{Sr}^{2+}, \mathrm{Eu}^{3+}[13]$, and $\mathrm{Co}^{2+}[20]$.

In this paper, MWCNTs are oxidized by nitric acid, and the obtained MWCNTs are amino-functionalized by ethylene diamine. Amino-functionalized MWCNTs are characterized by many techniques such as Fourier transform infrared spectroscopy (FTIR), thermogravimetric analysis (TGA) and Boehm titration. The Amino-functionalized MWCNTs are employed as new sorbents of SPE. Solid phase extraction of $\mathrm{Hg}^{2+}$ is carried out in real water and fish samples. These sorbents are also conducted to determine the optimal chemical modification of MWCNTs in water and wastewater treatment.

\section{Experimental}

2.1. Reagent. MWCNTs (OD $10-20 \mathrm{~nm}$, ID $5-10 \mathrm{~nm}$, length 5-15 $\mu \mathrm{m}$, and purity 95\%) were purchased from Shenzhen (China). Ethylenediaminetetraacetic acid (EDTA), methanol (HPLC grade), ethanol, propanol, $\mathrm{HgCl}_{2}, \mathrm{NaOH}, \mathrm{NaCl}$, $\mathrm{Cu}\left(\mathrm{NO}_{3}\right)_{2} \cdot 4 \mathrm{H}_{2} \mathrm{O}, \mathrm{Pb}\left(\mathrm{NO}_{3}\right)_{2}, \mathrm{Cd}\left(\mathrm{NO}_{3}\right)_{2} \cdot 4 \mathrm{H}_{2} \mathrm{O}, \mathrm{Ca}\left(\mathrm{NO}_{3}\right)_{2}$. $4 \mathrm{H}_{2} \mathrm{O}, \mathrm{MgCl}_{2} \cdot 6 \mathrm{H}_{2} \mathrm{O}, \mathrm{DMF}, \mathrm{THF}, \mathrm{SOCl}_{2}, \mathrm{HCl}(35 \%), \mathrm{HNO}_{3}$ (65\%), and Thiourea were of the highest purity available from Merck AG (Darmstadt, Germany). All the other chemicals were of analytical reagent grade. Stock solution of $\mathrm{Hg}^{2+}$ $(1000 \mu \mathrm{g} / \mathrm{mL})$ was prepared by dissolving a proper amount of $\mathrm{HgCl}_{2}$ in $50 \mathrm{~mL}$ of double distilled water.

2.2. Apparatus. $\mathrm{A} \mathrm{pH}$ is measured with a $\mathrm{B} 2000 \mathrm{pH}$ meter equipped with a GCFC 11 combination glass electrode. Determination of mercury is conducted with a flame atomic absorption spectrometer (FAAS) GBC model 902AA (GBC Scientific Equipment, Dandenong, VIC, Australia) using an air-acetylene flame in the optimization steps and an atomic absorption spectrometer model GBC 902AA with continuous flow hydride generator HG3000 in quantitative and real sample analysis. GBC HG 3000 continuous-flow vapor system equipped with a gas-liquid separator is used for $\mathrm{HgH}_{2}$ generation. A mercury hallow cathode lamp is used as a light source at $354 \mathrm{~nm}$ and $0.5 \mathrm{~nm}$ band width. FTIR spectra are recorded in the range of $400-4000 \mathrm{~cm}^{-1}$ using Bruker Tensor 27 FTIR spectrometer (Germany) by $\mathrm{KBr}$ pellets. The thermal analysis studies are carried out using TG/DTA-SII (Perkin Elmer, USA). A syringe is available from BD, USA $(5 \mathrm{~cm} \times 0.9 \mathrm{~cm}$ i.d.). All glassware containers are carefully treated with $2.0 \mathrm{M}$ nitric acid (guaranteed reagent) and rinsed with double distilled water.

2.3. Preparation of Oxidized MWCNTs. The oxidized MWCNTs are prepared by oxidizing of raw MWCNTs. MWCNTs $(0.3 \mathrm{~g})$ are dispersed into a flask containing $70 \mathrm{~mL} \mathrm{HNO}_{3}$ (65\%). The mixture is refluxed at $100^{\circ} \mathrm{C}$ for $120 \mathrm{~min}$ to oxidize MWCNTs (Figure 1(a)). After cooling to room temperature, the mixture is filtered through a $0.45 \mu \mathrm{m}$ PTFE filter, and the solid is washed with deionized water until the $\mathrm{pH}$ of the filtrate is 7. The filtered solid is then dried at $70^{\circ} \mathrm{C}$ for $2 \mathrm{~h}$. 


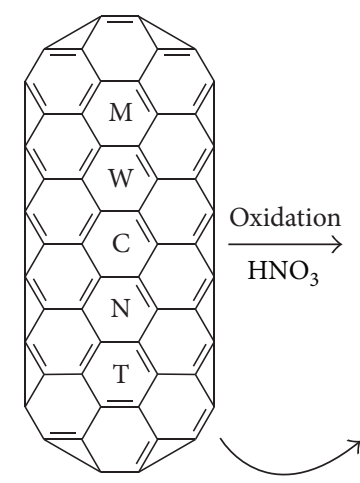

(a) Chemical reaction

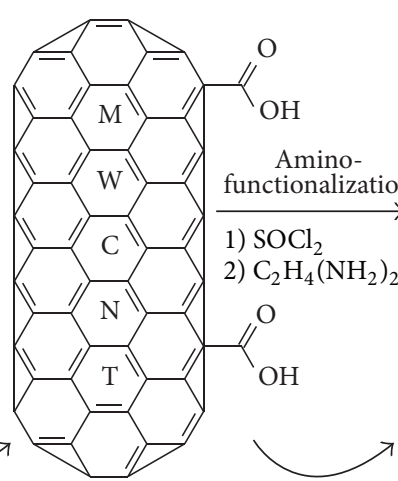

(b) Chemical reaction
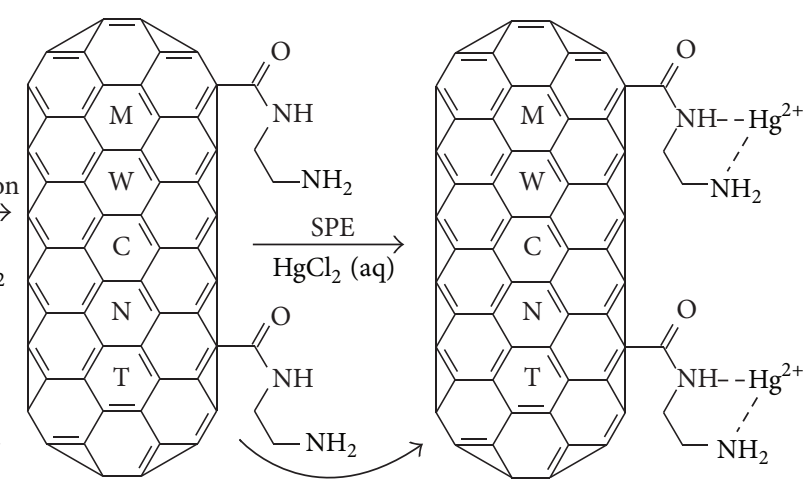

(c) Supramolecular interaction

FIGURE 1: Schematic illustration of amino-functionalization of MWCNTs ( $a$ and b) and solid phase extraction step (c). In the first step, MWCNTs are oxidized by $\mathrm{HNO}_{3}$ (a), and subsequently the oxidized MWCNTs are amino-functionalized by ethylenediamine (b). In the solid phase extraction step, mercury ions are adsorbed on the surface of amino-functionalized MWCNTs, and this is a kind of supramolecular interaction.

The obtained solid is used as purified MWCNTs in the next step [21].

2.4. Preparation of Acyl Chloride MWCNTs. To prepare the acyl chloride MWCNTs, the obtained oxidized MWCNTs $(0.3 \mathrm{~g})$ are suspended in $150 \mathrm{~mL}$ of $\mathrm{SOCl}_{2}$ and $50 \mathrm{~mL}$ tetrahydrofuran (THF). The suspension is treated with ultrasonic bath $(40 \mathrm{kHz})$ for $30 \mathrm{~min}$ and then stirred at $70^{\circ} \mathrm{C}$ for $24 \mathrm{~h}$ to convert the surface-bound carboxyl groups into acyl chloride groups. The solid is then filtered and washed with anhydrous THF. Subsequently, it is dried under vacuum at room temperature for $2 \mathrm{~h}[22,23]$. The obtained solid is applied in the amino-functionalization step.

2.5. Preparation of Amino-Functionalized MWCNTs. The amino-functionalized MWCNTs are prepared with aminofunctionalization of purified MWCNTs by ethylenediamine (see, Figure 1(b)). MWCNTs suspensions are prepared by dispersing $0.3 \mathrm{mg}$ of MWCNTs-COCl material in $50 \mathrm{~mL}$ of $\mathrm{N}, \mathrm{N}$-dimethylformamide (DMF) with the aid of ultrasonic agitation for $1 \mathrm{~h}$. The mixture is added with $5 \mathrm{~mL}$ of ethylenediamine under nitrogen; then it is heated at $70^{\circ} \mathrm{C}$ under stirring for $72 \mathrm{~h}$. Aliphatic multiamines are grafted onto MWCNTs through amide linkage. The resulting reaction medium is vacuum filtered through a $0.45 \mu \mathrm{m}$ PTFE membrane, then it is washed with acetone. The sample is dried at $80^{\circ} \mathrm{C}$ for $24 \mathrm{~h}$ and denoted as amino-MWCNTs, which is a mixture of mainly the amino-functionalized MWCNTs [24-27].

\subsection{Preparation of Amino-Functionalized MWCNTs Column.} The determination of $\mathrm{Hg}^{2+}$ is performed with continuous solid phase extraction with column. Amino-functionalized MWCNTs columns are prepared by packing the dry aminofunctionalized MWCNTs particles $(500 \mathrm{mg}$ ) in a $5 \mathrm{~mL}$ empty syringe. The syringe is attached with a stop cock and two sieve plates at the bottom end and the top end of aminofunctionalized MWCNTs packed particles. The sieve plates are obtained from commercial SPE cartridges. The aminofunctionalized MWCNTs columns are washed with $10 \mathrm{~mL}$ $0.1 \mathrm{M}$ EDTA for removing impurities. Before loading sample solutions, the polymer should be activated through $5 \mathrm{~mL}$ water rinse.

2.7. Solid Phase Extraction Step. The aqueous sample solutions $(10 \mathrm{~mL}, 50 \mathrm{mg} / \mathrm{L})$ of mercury ion are passed through amino-functionalized column at a flow rate of $1 \mathrm{~mL} / \mathrm{min}$ by vacuum system. As we observed in Figure 1(c), the mercury ion is adsorbed by amino-functionalized MWCNTs, and this is a kind of supramolecular interaction. After extracting, the extracted mercury ion is stripped from the column using EDTA solution $(2.5 \mathrm{~mL}, 0.1 \mathrm{M})$. Then, the concentration of mercury ion in effluent and eluent is determined by atomic absorption spectroscopy (a mercury hallow cathode lamp is used as a light source at $354 \mathrm{~nm}$ and $0.5 \mathrm{~nm}$ band width).

\section{Results and Discussion}

\subsection{Amino-Functionalized MWCNTs Characterization}

3.1.1. IR Spectra. Figure 2 illustrates the IR spectra of raw, oxidized, and amino-functionalized MWCNTs. All of the IR spectra of MWCNTs are recorded by using $\mathrm{KBr}$ pellet method. The IR spectra of raw, oxidized, and amino-functionalized MWCNTs showed similar characteristic peaks, indicating the similarity in the structure of the MWCNTs. Further, there are peaks at $\sim 1159$ and $1620 \mathrm{~cm}^{-1}$ in the IR spectra of oxidized MWCNTs corresponding to stretching of carbon-oxygen bond of lactone and asymmetric stretching of groups in the surface, respectively. In the raw MWCNTs, these peaks are not available. These results indicate that after the oxidation step, the oxygen functional groups such as carboxylic and lactone are formed on the surface of purified MWCNTs. There are peaks at $\sim 1159,1400$, and $1620 \mathrm{~cm}^{-1}$ in the IR spectra of amino-functionalized MWCNTs corresponding to stretching of carbon-oxygen bond 


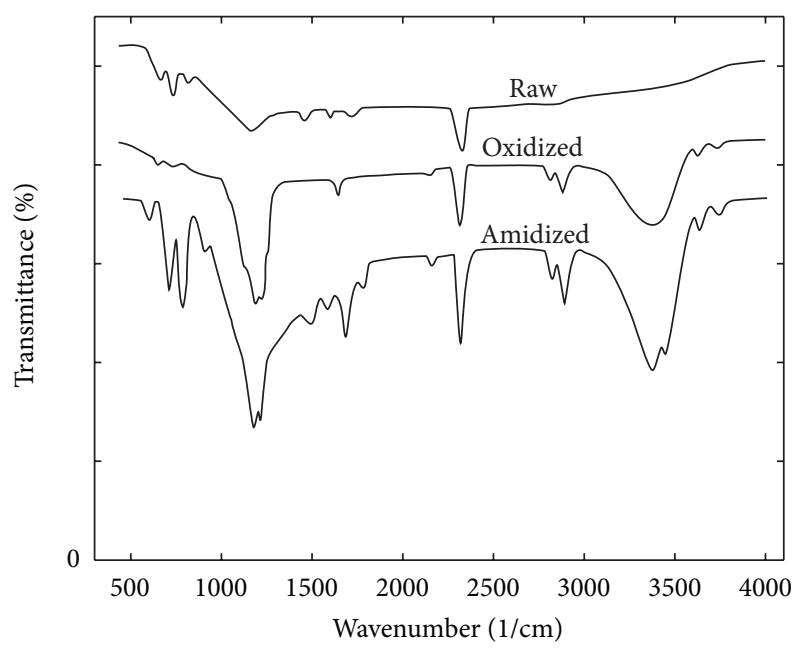

FIGURE 2: IR spectra of raw, oxidized, and amino-functionalized MWCNTs.

of lactone, carbon-nitrogen bond of amide, and asymmetric stretching of carboxylic groups of amide in the surface, respectively. There is no peak at $1400 \mathrm{~cm}^{-1}$ in the IR spectra of oxidized MWCNTs. These results indicate that, after aminofunctionalization step, the acyl chloride group is replaced with the amine group and also the nitrogen functional groups are formed on the surface of purified MWCNTs.

3.1.2. Thermogravimetric Analyses. It is useful to compare the TGA pattern of raw, oxidized, and amino-functionalized MWCNTs because in the functionalization process the functional groups are formed on the end and defect sites. The raw, oxidized, and amino-functionalized MWCNTs show similar TGA pattern, indicating the analogous thermal stability of these MWCNTs. The raw, oxidized, and aminofunctionalized MWCNTs are stable up to 650, 450, and 250, respectively. The raw MWCNTs are more stable than oxidized MWCNTs, and oxidized MWCNTs are more stable than amino-functionalized MWCNTs (Figure 3). The observed stabilized temperature is known to be strongly influenced by the step of the functionalization.

3.1.3. Boehm Titration. Oxygen functional groups are quantitatively evaluated using the Boehm titration method. The amount of carboxyl and total acidic site on the carbon surface is quantitatively chemically analyzed by titration. The amount of carboxylic and total acidic sites is determined by addition of $50 \mathrm{~mL}, 0.05 \mathrm{~N} \mathrm{NaHCO}_{3}, \mathrm{Na}_{2} \mathrm{CO}_{3}$, and $\mathrm{NaOH}$, respectively into $50 \mathrm{mg}$ purified and amino-functionalized MWCNTs and then stirred for 48 hours to reach an equilibrium state. Thereafter, the solution is filtrated to remove MWCNTs from clear solution. The removal of the MWCNTs from the titrated solution is essential to avoid $\mathrm{HCl}$ reacting with the deprotonated groups at MWCNTs surface, which would induce errors as well as slow down the titration. A part of filtrated solution $(10 \mathrm{~mL})$ is selected, and the titration is performed by $(0.1 \mathrm{~N}) \mathrm{HCl}$ solution to determine the excess of the base until the neutral solution is reached $[29,30]$.

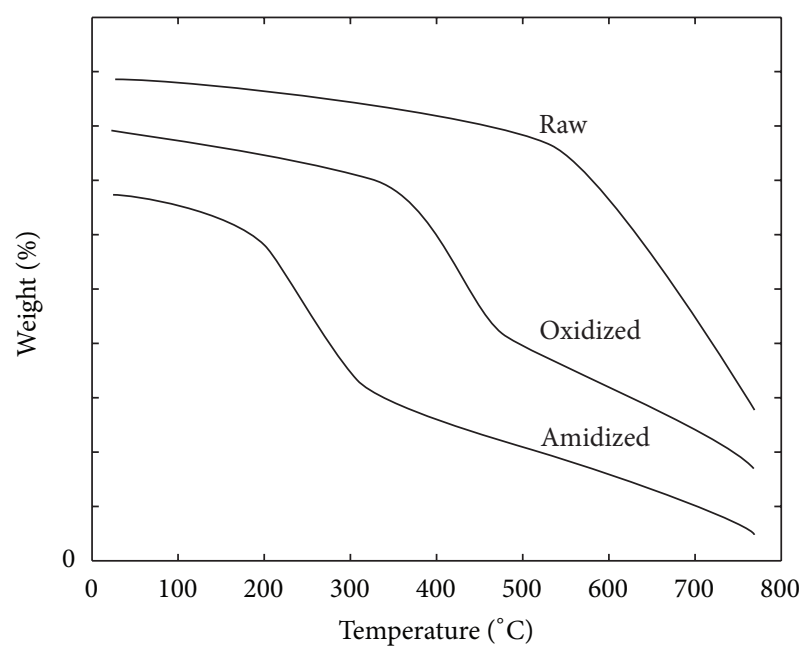

FIGURE 3: TGA plots of raw, oxidized, and amino-functionalized MWCNTs.

TABLE 1: Boehm titration of acidic group on the surface of purified and amino-functionalized MWCNTs.

\begin{tabular}{lcccc}
\hline \multirow{2}{*}{ Kind of MWCNTs } & \multicolumn{4}{c}{ Acidic group (mmol/g) } \\
& Total & Carboxyl & Lactone & Phenol \\
\hline $\begin{array}{l}\text { Purified MWCNTs } \\
\text { Amino-functionalized }\end{array}$ & 1.04 & 0.66 & 0.21 & 0.16 \\
MWCNTs & 1.04 & 0.66 & 0.21 & 0.16 \\
\hline
\end{tabular}

As seen in Table 1, the result of purified and aminofunctionalized MWCNTs are similar. The carboxyl group on the surface of purified and amino-functionalized MWCNTs is equal because amide groups like carboxylic group are a strong base, and they titrated with $\mathrm{Na}_{2} \mathrm{CO}_{3}$. It is found that the amount of carboxylic groups is not changed in aminofunctionalization step, but hydroxyl groups are changed to amide groups.

3.2. Optimization of Solid Phase Extraction. The percentage recovery is known to be strongly influenced by the many parameters. The effect of $\mathrm{pH}$ (1.5-7.5), sample matrix (acetate, formate, citrate, and phosphate buffers), flow rate of sample solution and eluent $(1-10 \mathrm{~mL} / \mathrm{min})$, aqueous phase and eluent volume $(10-300 \mathrm{~mL})$, nature of eluent $\left(\mathrm{CH}_{3} \mathrm{OH}, \mathrm{C}_{2} \mathrm{H}_{5} \mathrm{OH}\right.$, EDTA, thiourea, acetone, and $\mathrm{HCl}$ ), and concentration of eluent on percentage recovery is examined. All $\mathrm{Hg}^{2+}$ sample solutions which are used in the optimization step are prepared by diluting of stock solution.

3.2.1. Effect of $\mathrm{pH}$. The $\mathrm{pH}$ of aqueous phase is an important factor in a solid phase extraction procedure. Changes of $\mathrm{pH}$ can influence the reaction between $\mathrm{Hg}^{2+}$ and the amine group on the surface of amino-functionalized MWCNTs. To determine the effect of $\mathrm{pH}, \mathrm{pH}$ of solutions containing $50 \mu \mathrm{g} / \mathrm{mL} \mathrm{Hg}^{2+}$ onto amino-functionalized MWCNTs column is changed within the range of 1 to 7 . Figure 4 shows that mercury ions are effectively adsorbed at $\mathrm{pH}$ between 1 and 3 . 
The recovery of the adsorption decreases at $\mathrm{pH}$ higher than 3 due to the formation of mercury hydroxides. At strong acidic $\mathrm{pH}$, it is possible that the protonated amine group on the surface of functionalized MWCNTs and the percentage recovery decreases. Hence, subsequent extraction experiments are carried out at $\mathrm{pH} 3$.

3.2.2. Effect of Sample Matrix. It is anticipated that the sample matrix can affect the percentage recovery; so it is very necessary to examine the matrix effect in this work. The effect of sample matrix on the retention of mercury is investigated by adding $60 \mathrm{mM}$ acetate, citrate, formate, and phosphate buffers into the sample solution. The percentage recovery of the mercury ion for citrate, formate, phosphate, and acetate buffer is $91.48,95.12,75.23$, and 73.02, respectively. The percentage recovery of the mercury ion decreases with adding buffers because the tendency of acetate, citrate, and phosphate anions for the formation of noncharge ion pair with $\mathrm{Hg}^{2+}$ is strong and noncharge ion pair of $\mathrm{Hg}^{2+}$ cannot retain on the amino-functionalized MWCNTs column. As seen, the percentage recovery of $\mathrm{Hg}^{2+}$ cannot change with adding formate buffers, and the recoveries of $\mathrm{Hg}^{2+}$ decrease with adding acetate, citrate, and phosphate buffers. $\mathrm{Hg}^{2+}$ solution without any buffer is chosen as the optimal condition to separate analyte for all experiments.

3.2.3. Effect of Flow Rate of Sample. The effect of flow rate is an important parameter in the SPE method due to the time of analysis and contact time. To ensure quantitative recovery $(>95 \%)$, the effect of flow rate of sample solution is investigated. The flow rate of $1-5 \mathrm{~mL} / \mathrm{min}$ is found to be suitable for optimum loading of $\mathrm{Hg}^{2+}$ on the aminofunctionalized MWCNTs column. At higher flow rates (5$10 \mathrm{~mL} / \mathrm{min}$ ), there is a reduction in the percentage adsorption of mercury. This could be probably due to the insufficient contact time between the sample solution and column. A flow rate of $1 \mathrm{~mL} / \mathrm{min}$ is maintained as an optimal condition to analysis.

3.2.4. Effect of Sample Volume. Due to the low concentration of $\mathrm{Hg}^{2+}$ in real samples, these analytes should be taken into smaller volumes for high preconcentration factor by using sample solutions with large volumes. Therefore, the maximum applicable sample volume is determined by increasing the dilution of $\mathrm{Hg}^{2+}$ solution, while keeping the total amount of loaded $\mathrm{Hg}^{2+}$ fixed at $0.67 \mathrm{mg}$. Different feed volumes varied between 10 and $250 \mathrm{~mL}$. The results are given in Figure 5. As can be seen the recoveries of $\mathrm{Hg}^{2+}$ are quantitative up to $250 \mathrm{~mL}$ of sample volume. At volumes higher than $100 \mathrm{~mL}$, probably the analyte is not retained effectively because of passing excess of water through the column. So the $100 \mathrm{~mL}$ sample volume is selected as an optimum condition.

3.2.5. Effect of Choice of Eluent. The nature of the eluent is of prime importance and should meet three criteria: efficiency, selectivity, and compatibility [4]. Several eluent solutions such as propanol, ethanol, acetone, thiourea, EDTA, $\mathrm{HNO}_{3}$,

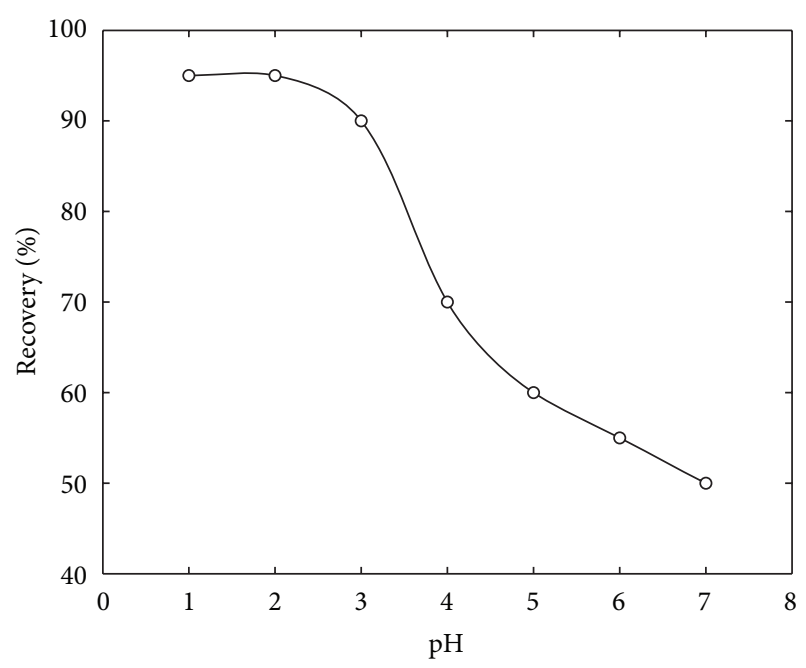

FIGURE 4: Effect of the $\mathrm{pH}$ on extraction efficiency.

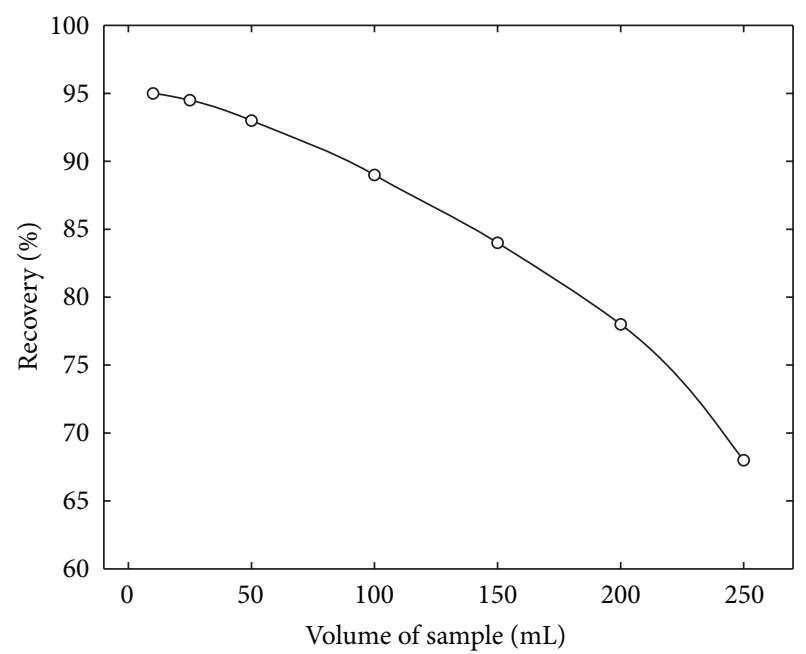

FIGURE 5: Effect of volume of sample on extraction efficiency.

$\mathrm{H}_{2} \mathrm{SO}_{4}$, and $\mathrm{HCl}$ are tested. As it is observed in Figure 6, a solution of EDTA at concentration of $0.1 \mathrm{M}$ is a proper solvent to elute $\mathrm{Hg}^{2+}$ from the column with $95 \%$ recovery. Higher concentration of EDTA has no effect on the recovery. The effectiveness of EDTA as an eluent may come from both its ability to produce stable complexes of $\mathrm{Hg}^{2+}$ that is not retained on the column and that $\mathrm{Hg}^{2+}$ is eluted from the column.

3.2.6. Effect of Volume of Eluent. According to the low concentration of mercury ion in real samples, these analytes must be taken into smaller eluent volume. The effect of eluent volume on the recovery of $\mathrm{Hg}^{2+}$ is investigated in the range from 0.5 to $10.0 \mathrm{~mL}$. The recoveries of $\mathrm{Hg}^{2+}$ increase significantly with the increasing eluent volume. The recovery of $\mathrm{Hg}^{2+}$ reached $95 \%$ by using only $2.5 \mathrm{~mL}$ eluent. At lower eluent volume, elution of $\mathrm{Hg}^{2+}$ decreases. Increasing the eluent volume further will result in dilution of the analytes. Thus, the volume of eluent is optimized as $2.5 \mathrm{~mL}$. 


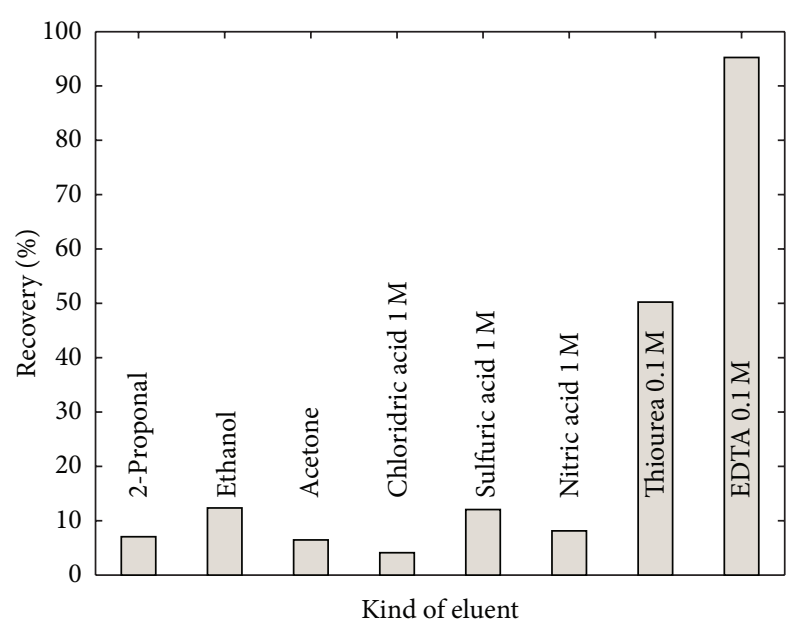

FIGURE 6: Effect of type of eluent on extraction efficiency.

TABLE 2: Selectivity test, recovery of different cations with respect to $\mathrm{Hg}^{+2}$.

\begin{tabular}{lccc}
\hline $\begin{array}{l}\text { Metal ion } \\
\left(\mathrm{M}^{n+}\right)\end{array}$ & $\begin{array}{c}\text { Concentration } \\
(\mu \mathrm{g} / \mathrm{mL})\end{array}$ & $\begin{array}{c}\text { Recovery of } \\
\mathrm{M}^{n+}(\%)\end{array}$ & $\begin{array}{c}\text { Recovery of } \\
\mathrm{Hg}^{2+}(\%)\end{array}$ \\
\hline $\mathrm{Fe}^{3+}$ & 100 & 68.64 & 95.01 \\
$\mathrm{Cu}^{2+}$ & 100 & 25.78 & 94.48 \\
$\mathrm{Ni}^{2+}$ & 100 & 22.75 & 85.43 \\
$\mathrm{Ca}^{2+}$ & 100 & 59.67 & 74.83 \\
$\mathrm{Mg}^{2+}$ & 100 & 45.32 & 63.29 \\
$\mathrm{Mn}^{2+}$ & 100 & 83.32 & 93.76 \\
\hline
\end{tabular}

Condition: the sample solution is $5 \mathrm{~mL}, 50 \mu \mathrm{g} / \mathrm{mL} \mathrm{Hg}^{+2}$, and $\mathrm{M}^{n+}$.

3.2.7. Effect of Flow Rate of Eluent. The eluent flow rate through the column is a very important parameter, since this is one of the steps that control the time of analysis. Therefore, the effect of the flow rate of eluent is examined under the optimum conditions $(\mathrm{pH}$, the sample volume and eluent, etc.). The flow rate is adjusted in a range of $1-5 \mathrm{~mL} / \mathrm{min}$. It is found that the analyte retention is not changed up to $5 \mathrm{~mL} / \mathrm{min}$ flow rate. Thus, a flow rate of $1.0 \mathrm{~mL} / \mathrm{min}$ is employed as an optimal condition.

3.2.8. Results of Selectivity Experiments. The effects of matrix ions for cold vapor atomic absorption spectrometric determinations on the recoveries of $\mathrm{Hg}^{2+}$ on amino-functionalized MWCNTs column are also investigated. The results are given in Table 2. A fixed amount of metal ions is taken with different amounts of foreign ions, and the recommended procedure is followed. The recovery of the analytes from the aminofunctionalized MWCNTs column is not affected by the solution containing the high concentrations of matrix ions. The tolerance limit of foreign ions is taken as that value which caused an error of not more than $\pm 30 \%$ in the absorbance. The ions normally present in water do not interfere under the used experimental conditions. Also, some of the transition metals at $\mathrm{mg} / \mathrm{L}$ did not interfere with the recoveries of the analyte ions on the amino-functionalized MWCNTs column. These
TABLE 3: Comparison of the analytical results on different CNTs adsorption methods.

\begin{tabular}{|c|c|c|c|}
\hline Metal & Kind of sorbent & $\begin{array}{c}\text { Adsorption } \\
\text { capacity (mg/g) }\end{array}$ & Reference \\
\hline $\mathrm{Hg}^{2+}$ & $\begin{array}{l}\text { Amino-functionalized } \\
\text { MWCNTs }\end{array}$ & 11.58 & This method \\
\hline $\mathrm{Pb}^{2+}$ & MWCNTs & $5.50-16.40$ & [6] \\
\hline $\mathrm{Pb}^{2+}$ & Oxidized MWCNTs & $22.5,59$ and 11.2 & [14-16] \\
\hline $\mathrm{Cd}^{2+}$ & Oxidized MWCNTs & $1.1-11$ & {$[16,18]$} \\
\hline $\mathrm{Ni}^{2+}$ & Oxidized MWCNTs & $9-47.85$ & {$[10]$} \\
\hline $\mathrm{Zn}^{2+}$ & Oxidized MWCNTs & $10.21-32.68$ & {$[18,19]$} \\
\hline $\mathrm{Cu}^{2+}$ & Oxidized MWCNTs & $7.5-11.3$ & {$[11,19]$} \\
\hline $\mathrm{Sr}^{2+} \& \mathrm{Eu}^{2+}$ & Oxidized MWCNTs & - & {$[13]$} \\
\hline $\mathrm{Co}^{2+}$ & $\begin{array}{l}\text { L-Tyrosine on } \\
\text { oxidized MWCNTs }\end{array}$ & $1.18-2.21$ & {$[28]$} \\
\hline
\end{tabular}

results show that the proposed preconcentration/separation method could be applied for mercury species to the highly saline samples and the samples that contain some transition metals.

3.2.9. Analytical Performance. At volumes higher than $100 \mathrm{~mL}$, probably the analyte is not retained effectively so the break-through volume for the method is greater than $100 \mathrm{~mL}$. After eluting the $\mathrm{Hg}^{2+}$, the final solution volume of $2.5 \mathrm{~mL}$ is achieved; therefore, the preconcentration factors of 40 are obtained. The maximum capacity of the cartridge is investigated by passing $5 \mathrm{~mL}$ of sample solutions containing $50-3000 \mu \mathrm{g} / \mathrm{mL}$ of $\mathrm{Hg}^{2+}$ ion through the column and followed by determination of the retained ions using atomic absorption spectrometry. The maximum capacity of the sorbent is $11.58 \mathrm{mg} / \mathrm{g}$. Calibration graphs are constructed with five standard solutions containing $\mathrm{Hg}^{2+}$ ion according to the general procedure. The linear range, regression equation, and correlation coefficient of the proposed method are 0.003 to $0.3 \mathrm{ng} / \mathrm{mL}, A=6.94 X-0.0042(\mathrm{ng} / \mathrm{mL})$, and 0.983 , respectively. The limit of detection and relative standard deviation (RSD) of the proposed method are $1.25 \times 10^{-3} \mu \mathrm{g} / \mathrm{L}$ and $2.23 \%$, respectively.

3.2.10. Comparison of the Analytical Results on Different CNTs Adsorption Methods. Comparison of functionalized MWCNTs for adsorption of $\mathrm{Hg}^{2+}$ with published papers included MWCNTs as a sorbent for adsorption of other metals which showed that the adsorption capacity of the sorbent is better than the other method (Table 3). The column packed with the amino-functionalized MWCNTs is suitable enough to separate $\mathrm{Hg}^{2+}$ from the complex matrixes containing interference ions such as $\mathrm{Fe}^{3+}, \mathrm{Cu}^{2+}, \mathrm{Pb}^{2+}, \mathrm{Ni}^{2+}$, $\mathrm{Mn}^{2+}, \mathrm{Ca}^{2+}$, and $\mathrm{Mg}^{2}$.

\section{Application}

The experimental protocol can be used for the determination of mercury ions in real samples with complex matrix. 
TABLE 4: Determination of $\mathrm{Hg}^{2+}$ in real samples.

\begin{tabular}{lccc}
\hline Sample & $\begin{array}{c}\text { Added } \mathrm{Hg}^{2+} \\
(\mathrm{ng} / \mathrm{mL})\end{array}$ & $\begin{array}{c}\text { Found } \mathrm{Hg}^{2+} \\
(\mathrm{ng} / \mathrm{mL})\end{array}$ & RSD (\%) \\
\hline \multirow{3}{*}{ Tap water (Karaj) } & 0 & 0.08 & 2.14 \\
& 0.25 & 0.32 & 3.32 \\
& 0.5 & 0.58 & 2.28 \\
& 0.75 & 0.84 & 2.42 \\
& 1 & 1.13 & 3.34 \\
\hline \multirow{3}{*}{ Seawater (Khazar) } & 0 & 0.06 & 3.76 \\
& 0.5 & 0.28 & 3.45 \\
& 0.75 & 0.62 & 2.76 \\
Fish & 1 & 0.86 & 4.32 \\
& 0 & 1.07 & 5.12 \\
\hline
\end{tabular}

Condition: the measurement is performed at optimum effective parameters and p.f. $=40$.

To validate the methodology, the proposed method for mercury determination is applied to analyze fish sample and natural waters. Trout fish from Karaj River, Seawater from Khazar Lake, and tap water from Karaj in Iran are subjected to the recommended procedure.

4.1. Analysis of Real Water Samples. It is anticipated that this method can eventually form a platform to measure mercury ion in water sample directly. The water samples are filtered through $0.45 \mu \mathrm{m}$ pore size millipore membrane filters; then the $\mathrm{pH}$ of these solutions is adjusted to the optimum level. This protocol is performed after standard addition of $\mathrm{Hg}^{2+}$. In the standard addition method, $100 \mathrm{~mL}$ of the samples is spiked with $0-1 \mathrm{ng} / \mathrm{mL}$ of $\mathrm{Hg}^{2+}$ ions before loading onto the column. Trace mercury in samples is preconcentrated by using this procedure. Upper aqueous solution is used for the determination of mercury by cold vapor atomic absorption spectrophotometry. The results are reported in Table 4 .

4.2. Analysis of Fish Samples. The key relevant application of detecting mercury ions is for food analysis. The detection of $\mathrm{Hg}^{2+}$ in fish samples is explored. The proposed method is applied to determine $\mathrm{Hg}^{2+}$ from fish sample. To digest this species, $500 \mathrm{mg}$ dried sample is placed in a digesting vessel, and $5 \mathrm{~mL} \mathrm{HNO}_{3}(70 \%)$ and $6 \mathrm{~mL} \mathrm{H}_{2} \mathrm{O}_{2}(30 \%)$ are added to the vessel. The vessel is immediately assembled, gently swirled, and placed in the preheated oven at $180^{\circ} \mathrm{C}$ for about 1.5 hours. About $6.0 \mathrm{~mL}$ of $1 \mathrm{M} \mathrm{K}_{2} \mathrm{SO}_{4}$ is added to the vessel; then the vessel is heated for $30 \mathrm{~min}$. The digested fish sample is cooled at room temperature. Appropriate amount of $2 \mathrm{M}$ $\mathrm{NaOH}$ is added to neutralize the excess of $\mathrm{HNO}_{3}$ and adjust $\mathrm{pH}$ at the optimized value (Table 4). The determination of mercury ions in the obtained solution is followed by this protocol [31,32].

\section{Conclusion}

The properties of MWCNTs such as purity, structure, and nature of the surface are greatly improved after aminofunctionalization which made them more hydrophilic and suitable for the adsorption of $\mathrm{Hg}^{2+}$ from aqueous solution. The functional groups are easily formed on the ends and at the defect sites. The $\mathrm{Hg}^{2+}$ adsorbed by amino-functionalized MWCNTs are mainly aggregated on the ends and at the defect sites on the amino-functionalized MWCNTs. The sorption mechanism appears mainly attributable to supramolecular interaction between the mercury ions and the surface functional groups of amino-functionalized MWCNTs which have a negative charge. Sorption/desorption study elucidated the possibility to reuse the spent MWCNTs for the removal of divalent $\mathrm{Hg}^{2+}$ in fish and real water samples.

\section{Acknowledgment}

The authors thank Imam Khomeini International University (IKIU) research council for financial support of this work.

\section{References}

[1] Y. G. Yin, M. Chen, J. F. Peng, J. F. Liu, and G. B. Jiang, "Dithizone-functionalized solid phase extraction-displacement elution-high performance liquid chromatography-inductively coupled plasma mass spectrometry for mercury speciation in water samples," Talanta, vol. 81, no. 4-5, pp. 1788-1792, 2010.

[2] L. G. Martin, L. T. Jongwana, and A. M. Crouch, "Capillary electrophoretic separation and post-column electrochemical detection of mercury and methyl mercury and applications to coal samples," Electrochimica Acta, vol. 55, no. 14, pp. 43034308, 2010.

[3] J. Fan, Y. Qin, C. Ye, P. Peng, and C. Wu, "Preparation of the diphenylcarbazone-functionalized silica gel and its application to on-line selective solid-phase extraction and determination of mercury by flow-injection spectrophotometry," Journal of Hazardous Materials, vol. 150, no. 2, pp. 343-350, 2008.

[4] C. He, W. Zhu, Y. Xu, T. Chen, and X. Qian, "Trace mercury (II) detection and separation in serum and water samples using a reusable bifunctional fluorescent sensor," Analytica Chimica Acta, vol. 651, no. 2, pp. 227-233, 2009.

[5] N. Amini, T. J. Cardwell, R. W. Cattrall, R. J. S. Morrison, and S. D. Kolev, "On-line determination of mercury(II) by membrane separation flow injection analysis," Talanta, vol. 63, no. 4, pp. 1069-1075, 2004.

[6] Y. H. Li, S. G. Wang, J. Q. Wei et al., "Lead adsorption on carbon nanotubes," Chemical Physics Letters, vol. 357, no. 3-4, pp. 263266, 2002.

[7] G. Wu, Z. Wang, J. Wang, and C. He, "Hierarchically imprinted organic-inorganic hybrid sorbent for selective separation of mercury ion from aqueous solution," Analytica Chimica Acta, vol. 582, no. 2, pp. 304-310, 2007.

[8] G. P. Rao, C. Lu, and F. Su, "Sorption of divalent metal ions from aqueous solution by carbon nanotubes: a review," Separation and Purification Technology, vol. 58, no. 1, pp. 224-231, 2007.

[9] Y. H. Li, S. G. Wang, Z. K. Luan, J. Ding, C. L. Xu, and D. H. Wu, "Adsorption of cadmium(II) from aqueous solution by surface oxidized carbon nanotubes," Carbon, vol. 41, no. 5, pp. 10571062,2003 
[10] C. Lu, C. Liu, and G. P. Rao, "Comparisons of sorbent cost for the removal of $\mathrm{Ni}^{2+}$ from aqueous solution by carbon nanotubes and granular activated carbon," Journal of Hazardous Materials, vol. 151, no. 1, pp. 239-246, 2008.

[11] C. Y. Kuo, "Water purification of removal aqueous copper (II) by as-grown and modified multi-walled carbon nanotubes," Desalination, vol. 249, no. 2, pp. 781-785, 2009.

[12] Y. H. Li, Y. Zhu, Y. Zhao, D. Wu, and Z. Luan, "Different morphologies of carbon nanotubes effect on the lead removal from aqueous solution," Diamond and Related Materials, vol. 15, no. 1, pp. 90-94, 2006.

[13] C. Chen, J. Hu, D. Xu, X. Tan, Y. Meng, and X. Wang, "Surface complexation modeling of $\mathrm{Sr}(\mathrm{II})$ and $\mathrm{Eu}(\mathrm{III})$ adsorption onto oxidized multiwall carbon nanotubes," Journal of Colloid and Interface Science, vol. 323, no. 1, pp. 33-41, 2008.

[14] J. Goel, K. Kadirvelu, C. Rajagopal, and V. K. Garg, "Removal of lead(II) by adsorption using treated granular activated carbon: batch and column studies," Journal of Hazardous Materials, vol. 125, no. 1-3, pp. 211-220, 2005.

[15] H. Wang, A. Zhou, F. Peng, H. Yu, and J. Yang, "Mechanism study on adsorption of acidified multiwalled carbon nanotubes to $\mathrm{Pb}(\mathrm{II})$," Journal of Colloid and Interface Science, vol. 316, no. 2, pp. 277-283, 2007.

[16] Y. H. Li, J. Ding, Z. Luan et al., "Competitive adsorption of $\mathrm{Pb}^{2+}$, $\mathrm{Cu}^{2+}$ and $\mathrm{Cd}^{2+}$ ions from aqueous solutions by multiwalled carbon nanotubes," Carbon, vol. 41, no. 14, pp. 2787-2792, 2003.

[17] H. Tavallali, S. Zahmatkesh, M. Aalaei, and D. Abdardideh, "Synthesis and application of glutaric dihydrazide modified multiwalled carbon nanotubes for selective solid-phase extraction and preconcentration of $\mathrm{Cu}(\mathrm{II}), \mathrm{Zn}(\mathrm{II}), \mathrm{Ni}(\mathrm{II})$, and $\mathrm{Fe}(\mathrm{III})$, Journal of AOAC International, vol. 95, no. 3, pp. 897-902, 2012.

[18] Z. A. ALOthman, M. Habila, E. Yilmaz, and M. Soylak, "Solid phase extraction of $\mathrm{Cd}(\mathrm{II}), \mathrm{Pb}(\mathrm{II}), \mathrm{Zn}(\mathrm{II})$ and $\mathrm{Ni}(\mathrm{II})$ from food samples using multiwalled carbon nanotubes impregnated with 4-(2-thiazolylazo)resorcinol," Microchimica Acta, vol. 177, no. 34, pp. 397-403, 2012.

[19] K. Pyrzynska and A. Stafiej, "Sorption behavior of $\mathrm{Cu}$ (II), $\mathrm{Pb}(\mathrm{II})$, and $\mathrm{Zn}(\mathrm{II})$ onto carbon nanotubes," Solvent Extraction and Ion Exchange, vol. 30, no. 1, pp. 41-53, 2012.

[20] H. Tavallali, D. Abdardideh, M. Aalaei, and S. Zahmatkesh, "New application of chemically modified multiwalled carbon nanotubes with thiosemicarbazide as a sorbent for separation and preconcentration of trace amounts of $\mathrm{Co}$ (II), $\mathrm{Cd}(\mathrm{II}), \mathrm{Cu}(\mathrm{II})$, and $\mathrm{Zn}(\mathrm{II})$ in environmental and biological samples prior to determination by flame atomic absorption spectrometry," Journal of the Chinese Chemical Society, vol. 59, no. 1, pp. 114121, 2012.

[21] F. Avilés, J. V. Cauich-Rodríguez, L. Moo-Tah, A. May-Pat, and R. Vargas-Coronado, "Evaluation of mild acid oxidation treatments for MWCNT functionalization," Carbon, vol. 47, no. 13, pp. 2970-2975, 2009.

[22] G. X. Chen and H. Shimizu, "Multiwalled carbon nanotubes grafted with polyhedral oligomeric silsesquioxane and its dispersion in poly(l-lactide) matrix," Polymer, vol. 49, no. 4, pp. 943-951, 2008.

[23] C. Zhou, S. Wang, Y. Zhang, Q. Zhuang, and Z. Han, "In situ preparation and continuous fiber spinning of poly(p-phenylene benzobisoxazole) composites with oligo-hydroxyamide-functionalized multi-walled carbon nanotubes," Polymer, vol. 49, no. 10, pp. 2520-2530, 2008.
[24] J. Zhang and D. Jiang, "Interconnected multi-walled carbon nanotubes reinforced polymer-matrix composites," Composites Science and Technology, vol. 71, no. 4, pp. 466-470, 2011.

[25] T. I. T. Okpalugo, P. Papakonstantinou, H. Murphy, J. McLaughlin, and N. M. D. Brown, "Oxidative functionalization of carbon nanotubes in atmospheric pressure filamentary dielectric barrier discharge (APDBD)," Carbon, vol. 43, no. 14, pp. 2951-2959, 2005.

[26] G. X. Chen, H. S. Kim, B. H. Park, and J. S. Yoon, "Multi-walled carbon nanotubes reinforced nylon 6 composites," Polymer, vol. 47, no. 13, pp. 4760-4767, 2006.

[27] Y. Li, Y. Zhao, Z. Zhang, and Y. Xu, "Amino-functionalized carbon nanotubes as nucleophilic scavengers in solution phase combinatorial synthesis," Tetrahedron Letters, vol. 51, no. 10, pp. 1434-1436, 2010.

[28] P. H. Pacheco, P. Smichowski, G. Polla, and L. D. Martinez, "Solid phase extraction of Co ions using l-tyrosine immobilized on multiwall carbon nanotubes," Talanta, vol. 79, no. 2, pp. 249253, 2009.

[29] S. L. Goertzen, K. D. Thériault, A. M. Oickle, A. C. Tarasuk, and H. A. Andreas, "Standardization of the Boehm titration-part I: $\mathrm{CO}_{2}$ expulsion and endpoint determination," Carbon, vol. 48, no. 4, pp. 1252-1261, 2010.

[30] A. M. Oickle, S. L. Goertzen, K. R. Hopper, Y. O. Abdalla, and H. A. Andreas, "Standardization of the Boehm titration-part II: method of agitation, effect of filtering and dilute titrant," Carbon, vol. 48, no. 12, pp. 3313-3322, 2010.

[31] M. Tüzen, "Determination of heavy metals in fish samples of the middle Black Sea (Turkey) by graphite furnace atomic absorption spectrometry," Food Chemistry, vol. 80, no. 1, pp. 119-123, 2003.

[32] N. Pourreza and K. Ghanemi, "Determination of mercury in water and fish samples by cold vapor atomic absorption spectrometry after solid phase extraction on agar modified with 2-mercaptobenzimidazole," Journal of Hazardous Materials, vol. 161, no. 2-3, pp. 982-987, 2009. 

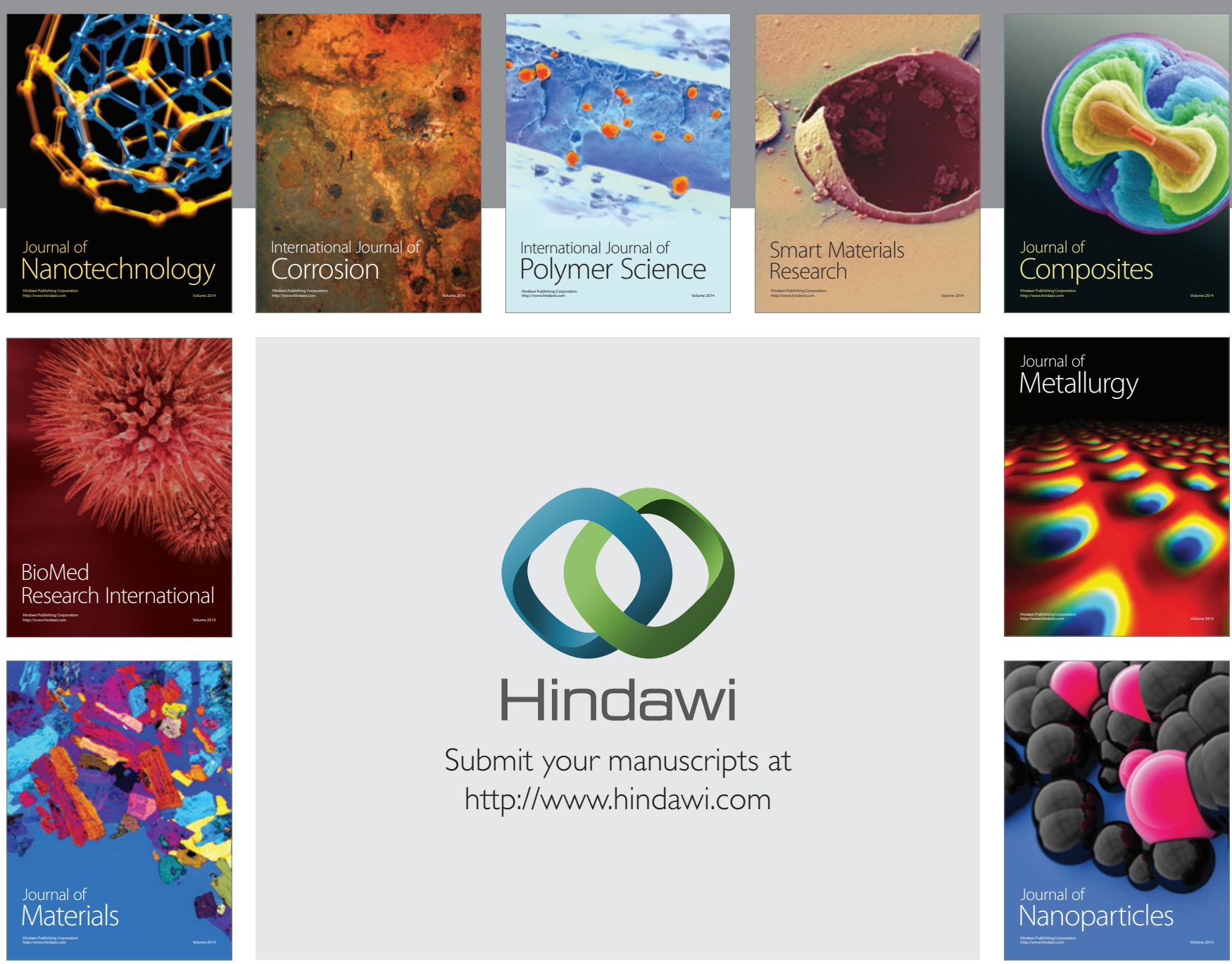

Submit your manuscripts at http://www.hindawi.com
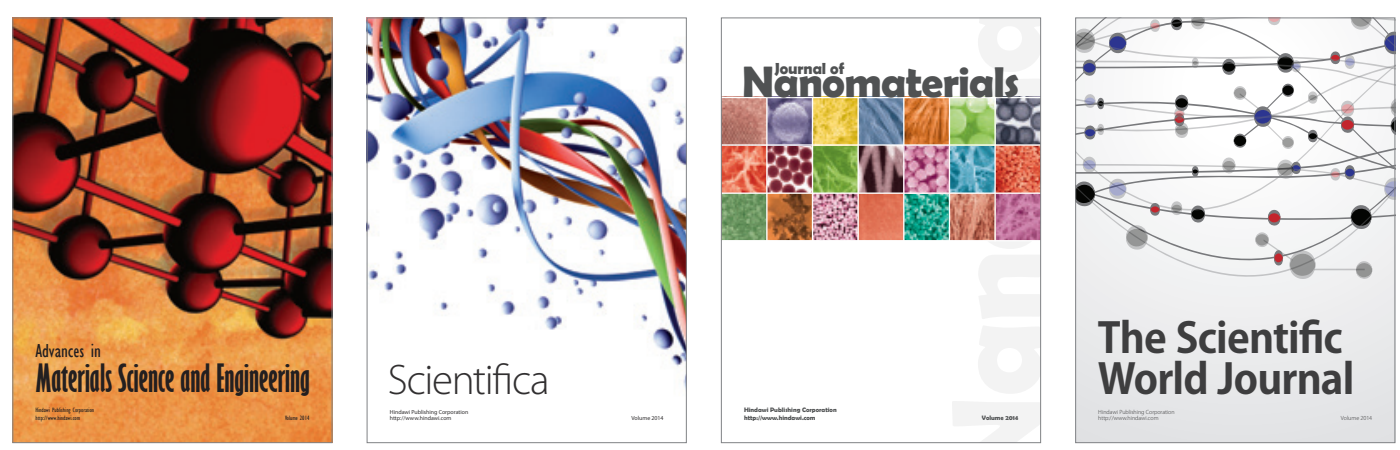

\section{The Scientific World Journal}
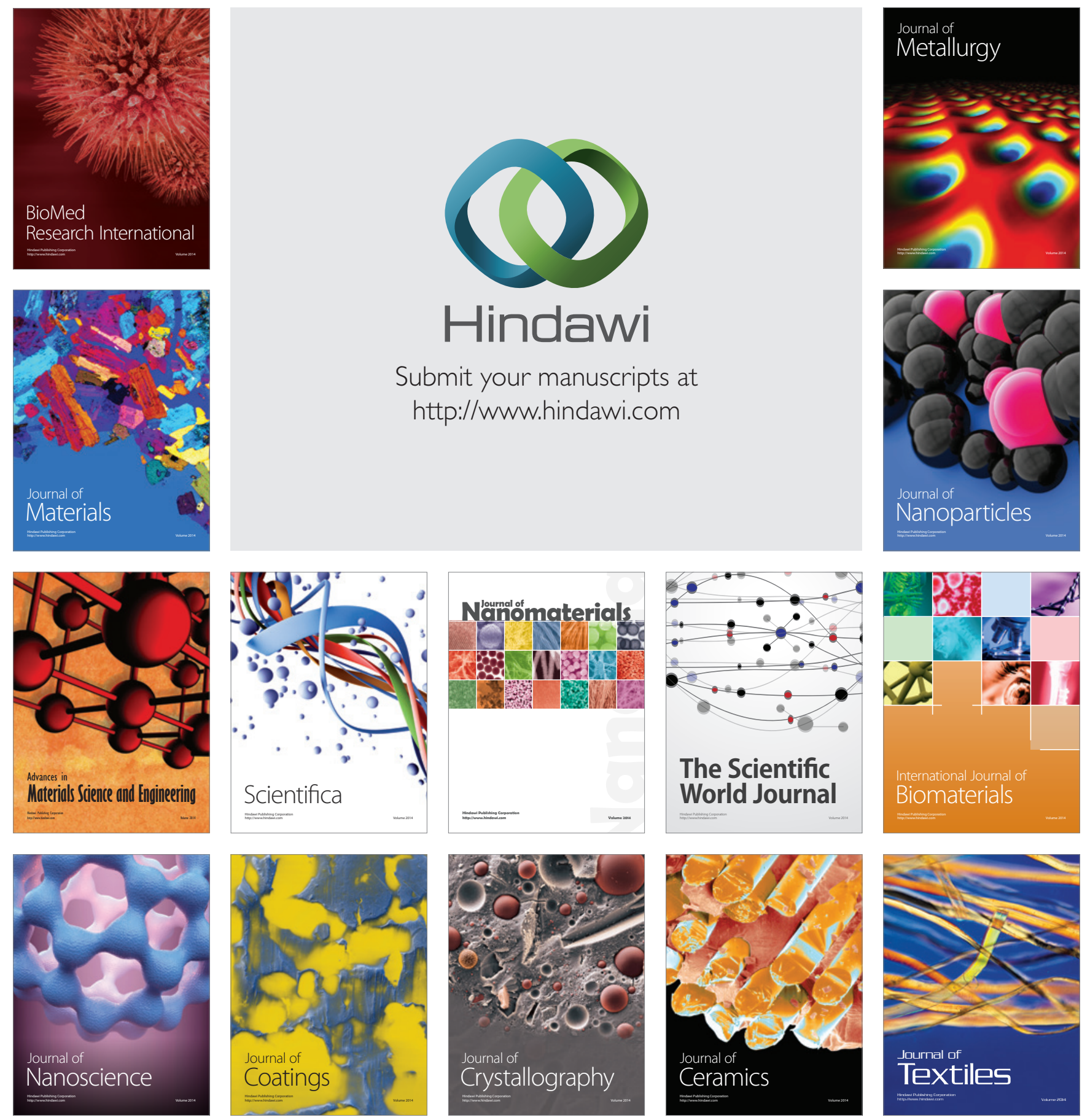